\title{
Osteomielitis de pubis. Reporte de caso
}

\author{
Sebastián Solernó, "Andrés Cattáneo," Macarena Ifran, " Osvaldo Romano** \\ "Servicio de Ortopedia y Traumatología, Hospital Mi Pueblo, Florencio Varela, Buenos Aires, Argentina \\ ${ }^{* *}$ Servicio de Ortopedia y Traumatología, Hospital El Cruce S.A.M.I.C, Florencio Varela, Buenos Aires, Argentina
}

\section{RESUMEN}

La osteomielitis de pubis es una enfermedad infrecuente $(<2 \%$ de todas las infecciones óseas) que rara vez se sospecha y su diagnóstico suele pasarse por alto, se la confunde fácilmente con pubalgias que no responden al tratamiento. Consideramos que la comunicación de este caso puede serle útil al traumatólogo para no olvidar este cuadro extremadamente infrecuente y disminuir el costo del diagnóstico y el tratamiento.

Palabras clave: Osteomielitis; pubis; biopsia ósea; Escherichia coli.

Nivel de Evidencia: IV

\section{Osteomyelitis Pubis. Case Report}

\section{ABSTRACT}

Osteomyelitis Pubis is a rare condition that represents less than $2 \%$ of bone infections. It is not usually suspected and it can be misdiagnosed, as it can be mistaken for pubalgia that does not respond to treatment. This report may be useful to other traumatologists so as not to forget this extremely rare condition and reduce the cost of diagnosis and treatment.

Key words: Osteomyelitis; pubis; bone biopsy; Escherichia coli.

Level of Evidence: IV

\section{INTRODUCCIÓN}

La infección ósea del pubis es una enfermedad rara y poco diagnosticada, que se confunde fácilmente con pubalgias no infecciosas. Según la bibliografía consultada, representa $<2 \%$ de todas las osteomielitis. ${ }^{1-3}$ Su presentación es insidiosa, por lo general, es un cuadro secundario a cirugías urológicas o ginecológicas, y se disemina por vía hematógena. Los errores de diagnóstico o el diagnóstico tardío son comunes debido a su frecuencia poco habitual. El objetivo de esta presentación es contribuir a que el traumatólogo tenga presente esta enfermedad al establecer los diagnósticos diferenciales.

\section{CASO CLÍNICO}

Mujer de 70 años de edad, sin antecedentes de enfermedades crónicas, que refiere haber sufrido un cuadro abdominal quirúrgico con peritonitis secundaria de origen apendicular. ${ }^{4-6}$ Este cuadro había sido tratado en otra institución pública, en octubre de 2018. Al segundo mes de la cirugía, tuvo una eventración en la zona del abordaje quirúrgico y dolor inguinal irradiado al pubis. El cuadro fue interpretado como dolor secundario a la eventración.

Los síntomas persistieron; fue dada de alta por su cirujano. En enero de 2019, acude a una consulta con su médico de cabecera, quien le solicitó estudios complementarios. La radiografía de pelvis no mostró evidencia de lesión. La ecografía abdominal mostró una cicatriz cutánea subyacente en la fosa ilíaca derecha, a 1,4 cm del plano cutáneo, una pequeña colección laminar de 49,8 x 20,6 x 3,4 mm asociada a edema de partes blandas adyacentes y una pequeña hernia inguinal con contenido graso y de reducción espontánea; saco herniario de 14,3 x 8,2 mm. No se observaron signos de eventraciones.

El cuadro clínico de pubalgia persistió, pese al tratamiento con analgésicos comunes e incluso derivados morfínicos (tramadol).

Recibido el 16-5-2020. Aceptado luego de la evaluación el 4-8-2020 • Dr. SEBASTIÁN SOLERNÓ • ssolerno@gmail.com 
En marzo de 2019, la paciente es derivada al Servicio de Ortopedia, ingresó deambulando con un andador (no lo necesitaba antes de la cirugía apendicular) y prefirió mantenerse en bipedestación durante la consulta.

En la anamnesis, manifestó sudoración nocturna y dolor 9/10 en el pubis con irradiación inguinal. Dicho dolor se exacerbaba cuando estaba sentada.

El examen físico reveló una tumoración sobre la cicatriz con tétrada de Celso, con extensión al pubis. Se constató hiperestesia con severa limitación durante la evaluación del pubis y de ambas caderas. La maniobra de "libro cerrado" en la pelvis exacerbó el dolor en el territorio púbico.

Los análisis bioquímicos arrojaron los siguientes resultados: leucocitos $16.500 / \mathrm{mm}^{3}$, eritrosedimentación $105 \mathrm{~mm}$ en la primera hora y proteína $\mathrm{C}$ reactiva $15,57 \mathrm{mg} / \mathrm{l}$. La radiografía actualizada (Figura 1) mostró una imagen de rarefacción ósea en la sínfisis púbica.

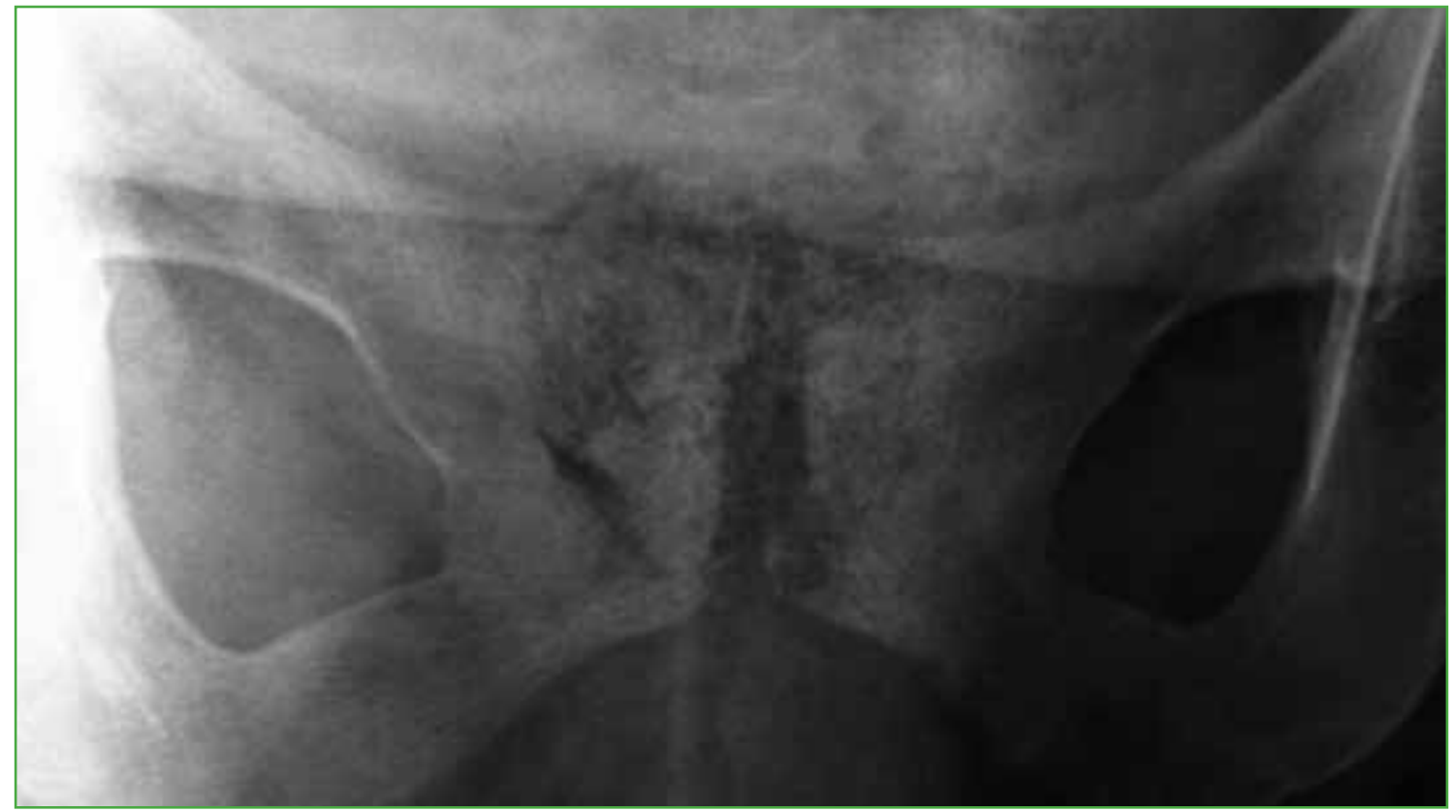

Figura 1. Radiografía de pelvis, de frente. Alteración de la estructura ósea del pubis.

Se completaron los estudios con una resonancia magnética con gadolinio y sin este medio de contraste (Figura 2). Se transcribe el informe de este estudio: "Osteítis púbica con irregularidad cortical ósea y edema óseo en ambas ramas pubianas a predominio del lado derecho; concomitantemente se observa colección líquida loculada con detritus celular y contenido de señal heterogénea en la interlínea articular del pubis, cuya dimensión es de 24 x 18 x $35 \mathrm{~mm}$ que impresiona como componente infeccioso-inflamatorio asociado, a valorar con antecedentes. Se observa imagen compatible con rotura parcial de la inserción proximal de músculos aductores a predominio derecho, edema miofibrilar de músculos aductores a predominio izquierdo". 

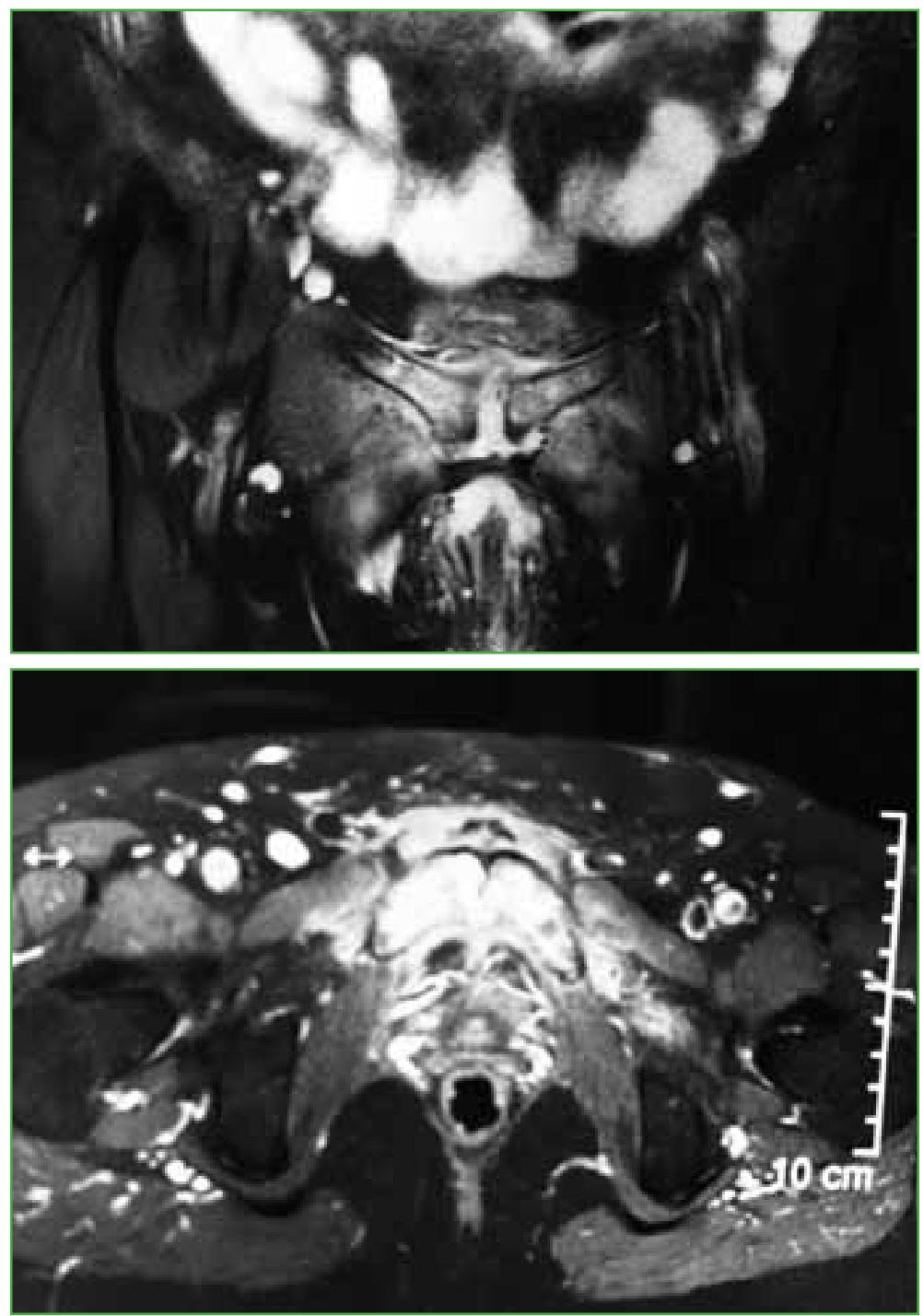

Figura 2. Resonancia magnética. Reacción edematosa ósea con alteración estructural cortical.

Con un diagnóstico probable de infección, se decidió realizar una biopsia ósea guiada por tomografía computarizada, ${ }^{7}$ la muestra fue enviada para estudios bacteriológico y anatomopatológico (Figura 3).

El examen directo bajo técnica de Ziehl-Neelsen fue negativo; en el cultivo, se halló un bacilo gramnegativo con tipificación para Escherichia coli. El antibiograma informó sensibilidad a trimetoprima/sulfametoxazol, piperacilina, cefalosporinas y norfloxacina.

Se le indicó trimetoprima/sulfametoxazol 160-800 mg por vía oral, cada $12 \mathrm{~h}$, durante 12 semanas. Tras la primera semana de tratamiento, se constató una importante mejoría del cuadro clínico. Al cabo de dos semanas, la paciente logró abandonar el andador y ya no necesitó ayuda para deambular.

Luego de los tres meses de tratamiento, se normalizaron los valores bioquímicos: leucocitos $8900 / \mathrm{mm}^{3}$, eritrosedimentación en la primera hora $12 \mathrm{~mm}$ y proteína C reactiva $6 \mathrm{mg} / \mathrm{l}$. A los $12 \mathrm{meses}$ del diagnóstico y el tratamiento, la paciente no tiene síntomas. 

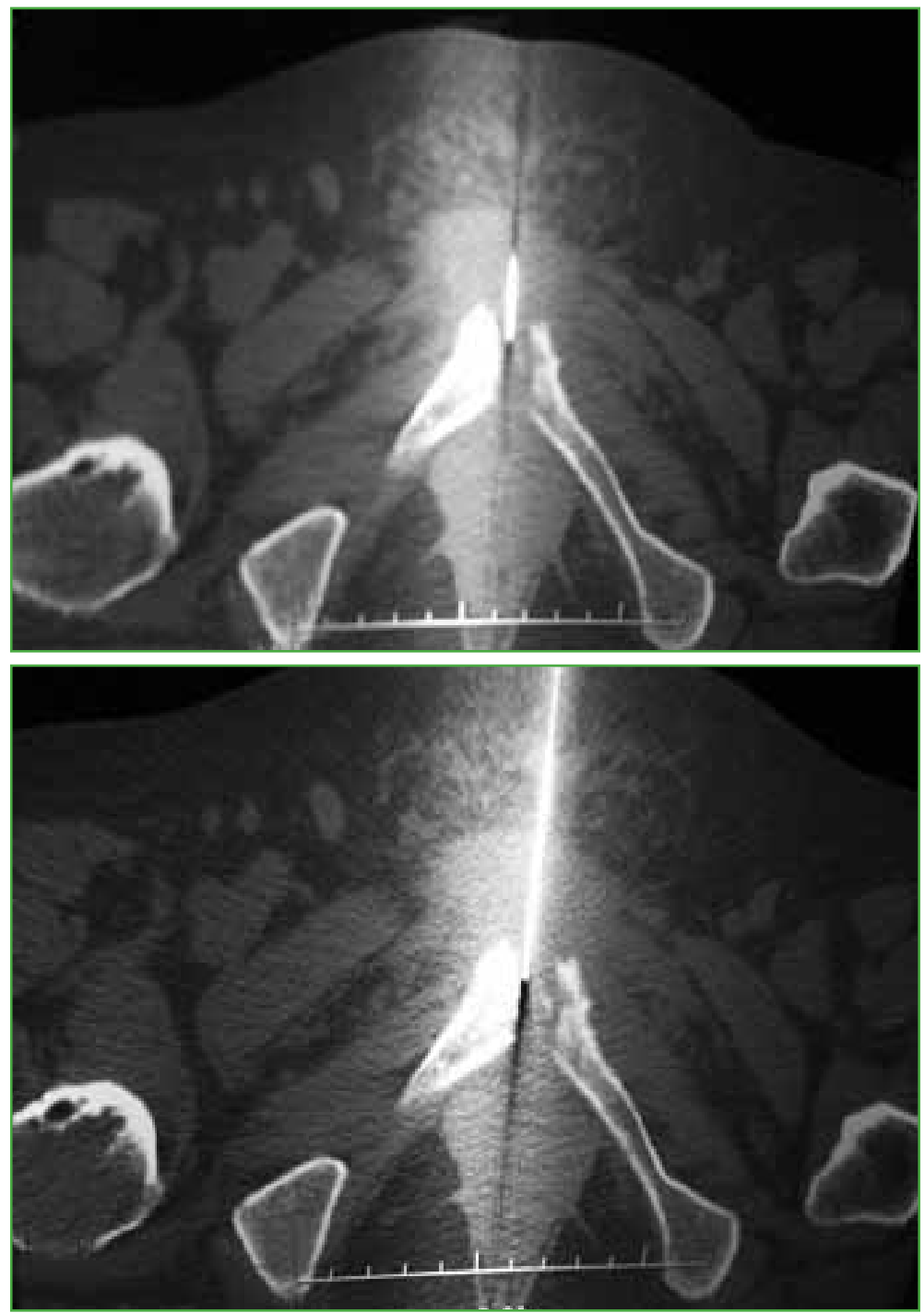

Figura 3. Aguja de punción ósea guiada bajo control tomográfico.

\section{DISCUSIÓN}

La osteomielitis de pubis es un cuadro que no hace distinción de edad o sexo, la vía hemática es la forma habitual de infección, generalmente secundaria a cirugías de pelvis, ginecológicas o urológicas. En pacientes deportistas, se la puede confundir fácilmente con pubalgias crónicas que no ceden con el tratamiento habitual. ${ }^{8}$ Los métodos de diagnóstico principales son los análisis bioquímicos, la resonancia magnética con gadolinio y sin gadolinio, y la biopsia ósea guiada por tomografía computarizada con toma de muestras óseas que deben ser enviadas para estudios bacteriológico y anatomopatológico. La tipificación del germen con su antibiograma no siempre es satisfactoria, aunque en nuestro caso, el resultado fue positivo y se indicó un tratamiento farmacológico durante 12 semanas.

La mejoría del cuadro clínico y la normalización de los parámetros bioquímicos nos hacen pensar que este proceso infeccioso está controlado. 


\section{CONCLUSIONES}

La osteomielitis de pubis es una enfermedad muy poco frecuente y posiblemente grave que puede ser confundida con una pubalgia que no responde al tratamiento, cuadro muy frecuente en deportistas. El correcto interrogatorio junto a una minuciosa anamnesis de los antecedentes personales, el examen físico meticuloso y el uso apropiado de estudios complementarios son los pilares fundamentales para obtener un diagnóstico certero temprano que permite prescribir un correcto tratamiento. Esta actitud disminuye la duración del proceso, el sufrimiento del paciente y optimiza el uso de los recursos económicos.

Conflicto de intereses: Los autores no declaran conflictos de intereses.

ORCID de A. Cattáneo: https://orcid.org/0000-0001-5254-0760

ORCID de M. Ifran: https://orcid.org/0000-0003-1562-8258

ORCID de O. Romano: https://orcid.org/0000-0002-3491-5538

\section{BIBLIOGRAFÍA}

1. Crenshaw AH. Campbell, Cirugía Ortopédica, 8a . ed. Buenos Aires: Editorial Médica Panamericana; 1993, vol. 2.

2. Tekin R, Ceylan Tekin R, Ceylan Cevik F, Cevik R. Acute osteomyelitis of the symphysis pubis after inguinal hernia surgery. Case Rep Rheumatol 2015;2015:845867. https://doi.org/10.1155/2015/845867

3. Rodero-Hernández J, Cabrerizo-García JL. Osteítis infecciosa del pubis. A propósito de un caso. Infectio 2016;20(4):269-71. https://doi.org/10.1016/j.infect.2015.10.007

4. Glasser JG. Case report: Osteitis/osteomyelitis pubis simulating acute appendicitis. Int J Surg Case Rep 2018;53:269-72. https://doi.org/10.1016/j.ijscr.2018.10.077

5. Pauli S, Willemsen P, Declerck K, Chappel R, Vanderveken M. Osteomyelitis pubis versus osteitis pubis: A case presentation and review of the literature. Br J Sports Med 2002;36(1):71-3. https://doi.org/10.1136/bjsm.36.1.71

6. Kitaguchi D, Enomoto T, Ohara Y, Oda T, Ohkohchi N. Pubic osteomyelitis after surgery for perforated colonic diverticulitis with fecal peritonitis: A case report. Int J Surg Case Rep 2017;38:50-2.

https://doi.org/10.1016/j.ijscr.2017.07.015

7. Schajowickz F, Ortolán E, Velán O, Santini Araujo E. Biopsia percutánea vertebral guiada por T.C. Rev Asoc Argent Ortop Traumatol 1985;50:44.

8. Andrews J, Rizzato Lede D, Senderovsky M, Finn B, Emery N, Bottaro F, et al. Artritis séptica del pubis en dos deportistas. Medicina (Buenos Aires) 2012;72(3):247-50. Disponible en:

https://pesquisa.bvsalud.org/portal/resource/pt/lil-657511 